\title{
L'Oragé, Douna Loup (Paris, Mercure de France, 2015)
}

Daniel Delas

Édition électronique
URL : https://journals.openedition.org/coma/609

DOI : $10.4000 /$ coma.609

ISSN : 2275-1742

\section{Éditeur}

Institut des textes \& manuscrits modernes (ITEM)

\section{Référence électronique}

Daniel Delas, «L'Oragé, Douna Loup (Paris, Mercure de France, 2015)», Continents manuscrits [En

ligne], Comptes-rendus de parutions, mis en ligne le 15 octobre 2015, consulté le 20 janvier 2023 URL : http://journals.openedition.org/coma/609 ; DOI : https://doi.org/10.4000/coma.609 


\title{
L'Oragé, Douna Loup (Paris, Mercure de France, 2015)
}

\author{
Daniel Delas
}

\section{RÉFÉRENCE}

L'Oragé, Douna Loup (Paris, Mercure de France, 2015)

$1 \quad$ Il semble impossible de dire du mal d'un roman animé d'une telle générosité et d'un tel amour pour l'amour. Les quelques critiques lues ici et là éclatent d'ailleurs en comparaisons élogieuses et exotiques, comme celles de la rubrique du Temps (22 août 2015): ce roman «se boit comme un jus de mangue» ou en adjectifs démesurés : « langue superbe », « rutilance », « bain chaud de couleurs et d'émotion » ${ }^{1}$, tant il est incontestable que Douna Loup a une écriture propre, sensuelle et invasive, qui nous met au contact quasi physique des sentiments les plus intimes des personnages.

2 Qui sont ces personnages ? D’abord la poétesse malgache Esther Razanadrasoa, dite Anja-Z (1893-1931), une femme de lettres originaire de Majunga et qui vécut une vie très libre, animée de liaisons avec des hommes européens ou malgaches, une amoureuse passionnée et changeante qui forme avec Jean-Joseph Rabearivelo le couple central du récit, avec un certain déséquilibre au détriment de "Rabe ", dont la personnalité comme homme ou comme écrivain n'est pas scrutée avec la même acuité que celle d'Esther.

3 Nous sommes dans l'immédiat après-guerre, au début des années 20, dans un pays colonisé dirigé par des administrateurs racistes, ce qu'en contrepoint évoquent des entrefilets de la presse de l'époque. Le contexte historique n'est toutefois qu'effleuré et on se demande si un lecteur ignorant des réalités malgaches de l'époque comprendra tous les tourments des personnages. Certes Esther et Rabe mènent une vie très libre fêtes alcoolisées, amours multiples et bivalents - mais leur pays n'est pas libre et les élites malgaches sont humiliées. Au fil des épisodes affectifs de ces vies, relatés avec 
chaleur et détail et qui occupent l'essentiel du livre, Rabearivelo se trouve lui-même dans et par la vérité de son écriture, ce que Dona Loup dit dans les dernières pages de son roman en décrivant sa mue en termes triomphalistes.

4 Triomphalistes, peut-être trop d'ailleurs, car le concept de langue qu'elle utilise, abondamment répété dans le livre, est ici trop simple : « Rabe marche en poète. Il sait ce qu'il devient. Il devient une langue. Au centre de lui-même dans cet espace qui tiraillait, cet espace de bataille entre les deux langues aimées, là dans ce centre-là qui a fait son tumulte est née une langue à soi, une langue au-delà qui inclut et surpasse. Il marche dans la nuit et il est cette langue.» (p. 222). Même martelé, ce terme ne suffit pas à rendre compte du cheminement douloureux de JJR «entre les langues » car un écrivain ne devient pas une langue mais l'écriture d'une langue, laquelle peut être issue de deux langues.

Douna Loup jongle avec les mots, les pèse, les soupèse, les tourne, les retourne et nous mène près, avec tout son amour à elle, tout près du souffle vital des deux poètes qu'elle aime mais cette belle approche poétique ne lui permet sans doute pas de dire ni l'épaisseur poisseuse de l'histoire coloniale dans laquelle ils ont vécu et qui explique leur mélancolie profonde ni les lacis complexes du colinguisme scripturaire qui fait de tout écrivain plurilingue un cas particulier d'équilibrage.

6 Revenons pour finir à l'étrange titre de cet étrange roman : L'Oragé. Le terme est un néologisme dérivé de "orage» qui donne en français ordinaire "orageux»; la dérivation inventée sur le modèle « dot » / "doté » fait de Rabe une victime des orages de l'histoire tout en le rapprochant de "enragé » pour dire le rebelle. Subtil, subtil, trop subtil. Pourquoi ne pas laisser parler les mots simples de la vie?

\section{NOTES}

1. http://www.letemps.ch/Page/Uuid/9a7f10bc-497f-11e5-85d0-41b5fd577541/

Douna_Loup_la_liberté_décrire_et_daimer 